\title{
Note from the Editor
}

Subscribers need to know about significant changes underway for the journal. First, readers will note that the subscription procedures page at the end of the issue has been completely revamped. The subscription page describes our new online membership system, about which we will also inform individual and institutional members directly. This new online membership system is one of a series of pending measures that will integrate more digital dimensions into the journal's operation without downplaying the customary purposes and character of a historical journal. The online membership system will be linked to the website, www.jgape.org, a new version of which should be in operation by the time this issue reaches subscribers. On the revised website, John McClymer, the new online editor, offers examples of digital features that build from the content of the conventional journal but that take distinct advantage of online formats. Henceforth such interactions, for example between articles and online curricular projects, will be a central aspect of the journal, as explained in the July 2009 editor's note. As the new website explains, the editors invite digital projects as much as they invite manuscript submissions.

There are, of course, downsides to these efforts at expansion and improvement. Last spring, the SHGAPE membership meeting accepted the recommendation of the ad hoc committee reviewing the society's business to raise membership rates by $\$ 10$ for all member categories except students, whose membership fee will rise from $\$ 15$ to $\$ 20$. This is the first rate increase in the history of the journal, and it was authorized after considerable discussion. The increase will cover extra costs related to two matters: the online membership system introduced above and the greater length of the journal.

As readers should have noticed, since 2007 we have expanded the journal from three to four articles and from three or four to five or six reviews (depending on the nature of the reviews). This increased length results from gradually increased popularity with authors as well as readers. Annual volume lengths have gone from around 420 pages to 540 pages and more. Since the journal is in healthy financial shape, especially given the overall financial condition of higher education, the society decided to pass on to subscribers only the additional costs for printing and mailing the longer journals and for management of the new online systems. That is, we wanted members only to pay more because they were getting that much more. We believe that price increases should be based on documentable and justifiable increased expenses, and in comparison to similar journals, this journal is still reasonably priced. Our current rates should be viable for at least several years. The only upcoming matter that would likely cause us to revisit rates 
relates to the handling of the online edition. This will again amount to a large improvement for subscribers, but we will try to avoid any effect upon rates.

One final change is evident in different places in this issue: As of January 2010, the business operations of SHGAPE will move from the R.B. Hayes Presidential Center to Indiana University, where they will be overseen by Wendy Gamber, the SHGAPE executive secretary. As readers can imagine, budget problems in Ohio precipitated this change, which eventually had to happen but which takes places years sooner than hoped. The staff at the Hayes Center has managed the society's business since SHGAPE's founding in the late 1980s; the center provided the institutional stability and oversight that enabled this journal to become established. Indiana University is of course a hub for the publication of historical journals, and the connection to Indiana will be highly useful to us as journal publishing grows more international and incorporates more digital dimensions. Still, the Hayes Center provided generous and loyal protection when we were starting out, and it will remain a valued institutional partner.

Subscribers can judge whether the journal is managed responsibly. Perhaps this issue falls short in terms of fiscal responsibility, because it contains a forum questioning the periodization concept of a Gilded Age, our second such forum since 2006. Whatever the journal might gain in terms of intellectual coherence and historical validity, it would lose in brand recognition if we took the advice of Rebecca Edwards and Richard John and dropped the "Gilded Age" in our title. And we would have to change the stationery.

While 1910 s and 1920s cultural critics affixed the name "Gilded Age" to the late 1800 s, they did not draw the name from thin air. This issue contains our first article ever on the person who, along with Charles Dudley Warner, wrote the novel and play from which half our name indeed derives. Fittingly, Robert Weir's article on Mark Twain in New Zealand is not about historical analysis but rather theatrical performance, particularly how Samuel Clemens adapted stories and routines that presumed American reference points for an audience halfway around the globe, when popular culture was only partly transnational.

The remaining articles-by William Murphy on the National Progressive Republican League and Nancy Rosenbloom on Thomas Ince's social-problem films - examine dimensions of the politics and culture of progressivism. Historians have gone around in circles for decades about the concept of a progressive movement, but surely the notion of a progressive mindset and tendency has a strong basis in the way disparate groups talked and acted in 1900-20. It is fascinating intellectual puzzle that for many decades historians who have assailed the Progressive Era have given the Gilded Age the benefit of the doubt. 